\title{
Catastrophic antiphospholipid syndrome as a complication of systemic sclerosis
}

\author{
D.J. Manzella', L. Vicente ${ }^{1}$, A.A. Pérez de la Hoz', R.J. Zamora', \\ G. De Rosa', A.A. Pisarevsky' \\ ${ }^{1}$ Department of Medicine; '2Department of Pathology, Hospital de Clínicas José de San Martín, \\ University of Buenos Aires, Buenos Aires, Argentina
}

\begin{abstract}
SUMMARY
A 62-year-old man with a history of systemic sclerosis was admitted with diffuse alveolar hemorrhage and acute kidney injury without clinical data suggestive of glomerulonephritis. Laboratory tests showed anemia, leukocytosis with neutrophilia, thrombocytopenia, elevated serum creatinine and metabolic acidosis. Antinuclear antibodies were positive at a titer of 1/640 (speckled, 1/160; nucleolar, 1/320) while rheumatoid factor, anti Scl-70, anti-centromere, anti-neutrophil cytoplasmic antibody and anti-glomerular basement membrane antibodies were negative and serum complement levels were within normal range. During the following days, the patient developed multiple organ failure and, eventually, died. Lupus anticoagulant was revealed positive after the patient's death, suggesting a catastrophic antiphospholipid syndrome. Clinical data and autopsy were consistent with this diagnosis.
\end{abstract}

Key words: Systemic sclerosis; catastrophic antiphospholipid syndrome; pulmonary renal syndrome; multiple organ failure.

Reumatismo, 2019; 71 (2): 92-98

\section{INTRODUCTION}

atastrophic antiphospholipid syndrome

(CAPS) is a frequently fatal and potentially underdiagnosed entity. As the regular form of antiphospholipid syndrome (APS), it appears either as a primary condition or in the setting of an underlying systemic autoimmune disease.

Even though CAPS has been described as a complication of systemic sclerosis ( $\mathrm{SSc}$ ), it is not systematically investigated when compatible signs and symptoms develop in a patient with this autoimmune disease. Moreover, the scleroderma pulmonary renal syndrome described by some authors $(1,2)$ can misguide the diagnostic strategy towards a pulmonary renal syndrome without consideration of CAPS. As they are different entities with their own pathophysiology and specific therapeutic implications, it is important to take CAPS into account when the likely setting arises.

\section{CASE REPORT}

A 62-year-old man was admitted to our hospital with the chief complaint of cough, bloody expectoration and dyspnea which had started $48 \mathrm{~h}$ before. He had a history of systemic sclerosis diagnosed four years before, arterial hypertension and a squamous cell carcinoma on his ear lobe treated surgically the previous year. $\mathrm{He}$ was receiving enalapril $2.5 \mathrm{mg}$, omeprazole 20 $\mathrm{mg}$, nifedipine $10 \mathrm{mg}$ and cilostazol $50 \mathrm{mg}$ daily. The last two drugs had been added one week earlier due to the insidious onset of cyanosis and pain on his right fifth toe. On observation, he looked acutely ill. His skin was diffusely thickened and hardened. Arterial tension was mildly elevated $(150 / 100 \mathrm{mmHg})$ as was the heart rate (113/min). He had sclerodactyly on both hands and the right fifth toe was cyanotic, cold and tender. He exhibited a tachypneic ventilation, percussion of both lung fields 
was resonant except for the lower area and auscultation revealed crepitations on the lower left region. Fundoscopy was normal. Laboratory findings on admission (Table 1) included normocytic anemia (hematocrit, 33\%; hemoglobin, $10.5 \mathrm{~g} / \mathrm{L}$; MCV, 94 $\mathrm{fL}$ ), leukocytosis with neutrophilia (WBC, $18,390 / \mathrm{mm}^{3}$; neutrophils, $\left.13,040 / \mathrm{mm}^{3}\right)$, thrombocytopenia (platelets, 104,000/ $\mathrm{mm}^{3}$ ), acute kidney injury (serum creatinine, $3.25 \mathrm{mg} / \mathrm{dL}$ ) and metabolic acidosis. Antinuclear antibodies (ANA) were positive at a titer of 1/640 (speckled, 1/160; nucleolar, 1/320). Rheumatoid factor (RF), anti Scl-70, anti-centromere (ACA), antineutrophil cytoplasmic antibody (ANCA) and anti-glomerular basement membrane (GBM) antibodies were negative and serum complement levels were within normal range.

A chest X-ray showed an enlarged cardiac silhouette and blunting of the costophrenic angles. A CT scan of the thorax (Figure 1) showed bilateral pleural and pericardial effusion and patchy areas of ground-glass opacification on the lung parenchyma. Renal ultrasound was unremarkable and cardiac ultrasound showed a moderate pericardial effusion without impairment of the right chambers. Systolic function of both ventricles was normal.

Peripheral blood smear showed anisocytosis, acanthocytosis and echinocytosis but no schistocytosis. Urinalysis revealed a density of 1020 , traces of proteinuria $(2+$ on dipstick method), 40-60 isomorphic erythrocytes and 4-6 granular casts per field of view.

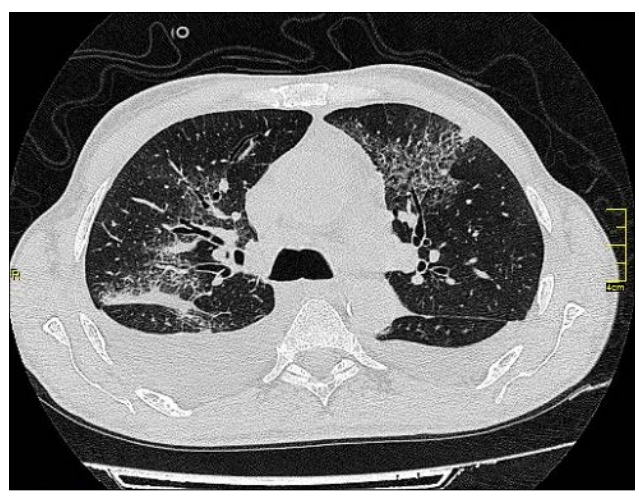

Figure 1
Table 1 - Laboratory results on admission.

\begin{tabular}{|c|c|c|}
\hline Laboratory test & Value & Normal range \\
\hline Hematocrit & $33 \%$ & $36-41 \%$ \\
\hline Hemoglobin & $10.5 \mathrm{~g} / \mathrm{dL}$ & $12-14 \mathrm{~g} / \mathrm{dL}$ \\
\hline Leukocytes & $18,390 / \mu \mathrm{L}$ & $4000-11,000 / \mu \mathrm{L}$ \\
\hline Platelets & $104,000 / \mu \mathrm{L}$ & $150,000-400,000 / \mu \mathrm{L}$ \\
\hline Urea & $118 \mathrm{mg} / \mathrm{dL}$ & $10-50 \mathrm{mg} / \mathrm{dL}$ \\
\hline Creatinine & $3.25 \mathrm{mg} / \mathrm{dL}$ & $0.4-1.10 \mathrm{mg} / \mathrm{dL}$ \\
\hline $\mathrm{Na}+$ & $137 \mathrm{mEq} / \mathrm{L}$ & $135-145 \mathrm{mEq} / \mathrm{L}$ \\
\hline $\mathrm{K}_{+}$ & $5.3 \mathrm{mEq} / \mathrm{L}$ & 3.5-5 mEq/L \\
\hline $\mathrm{Cl}-$ & $103 \mathrm{mEq} / \mathrm{L}$ & 98-107 mEq/L \\
\hline Total bilirubin & $0.5 \mathrm{mg} / \mathrm{dL}$ & $0-1 \mathrm{mg} / \mathrm{dL}$ \\
\hline AST & $13 \mathrm{U} / \mathrm{L}$ & $0-31 \mathrm{U} / \mathrm{L}$ \\
\hline ALT & $9 \mathrm{U} / \mathrm{L}$ & $0-31 \mathrm{U} / \mathrm{L}$ \\
\hline Alkaline phosphatase & $59 \mathrm{U} / \mathrm{L}$ & 35-104 U/L \\
\hline Lactate dehydrogenase & $622 \mathrm{U} / \mathrm{L}$ & $230-480 \mathrm{U} / \mathrm{L}$ \\
\hline ESR & $75 \mathrm{~mm} / \mathrm{hr}$ & $3-15 \mathrm{~mm} / \mathrm{hr}$ \\
\hline CRP & $15.82 \mathrm{mg} / \mathrm{dL}$ & $\leq 0.5 \mathrm{mg} / \mathrm{dL}$ \\
\hline Total proteins & $5.3 \mathrm{~g} / \mathrm{dL}$ & $6.4-8.0 \mathrm{~g} / \mathrm{dL}$ \\
\hline Serum albumin & $2.12 \mathrm{~g} / \mathrm{dL}$ & $3.9-4.9 \mathrm{~g} / \mathrm{dL}$ \\
\hline HIV & Negative & Negative \\
\hline Antinuclear antibody (ANA) & $1: 640$ & $<1: 40$ \\
\hline ANCA & Negative & Negative \\
\hline $\begin{array}{l}\text { Anti glomerular basement } \\
\text { membrane }\end{array}$ & Negative & Negative \\
\hline Rheumatoid factor & Negative & $<1: 20$ \\
\hline Anti Scl-70 & Negative & Negative \\
\hline Anticentromere & Negative & Negative \\
\hline Anti-Sm & Negative & Negative \\
\hline Anti-RNP & Negative & Negative \\
\hline Anti-dsDNA & Negative & Negative \\
\hline Anti-Ro/Ssa & Negative & Negative \\
\hline Anti-La/Ssb & Negative & Negative \\
\hline Lupus anticoagulant & Positive & Negative \\
\hline Anticardiolipin antibodies & Negative & Negative \\
\hline Anti-beta2-glycoprotein I & Negative & Negative \\
\hline $\mathrm{CH} 50$ & $34 / \mathrm{mL}$ & $25-50 / \mathrm{mL}$ \\
\hline C3 & $93 \mathrm{mg} / \mathrm{dL}$ & $80-180 \mathrm{mg} / \mathrm{dL}$ \\
\hline C4 & $16 \mathrm{mg} / \mathrm{dL}$ & $20-50 \mathrm{mg} / \mathrm{dL}$ \\
\hline
\end{tabular}




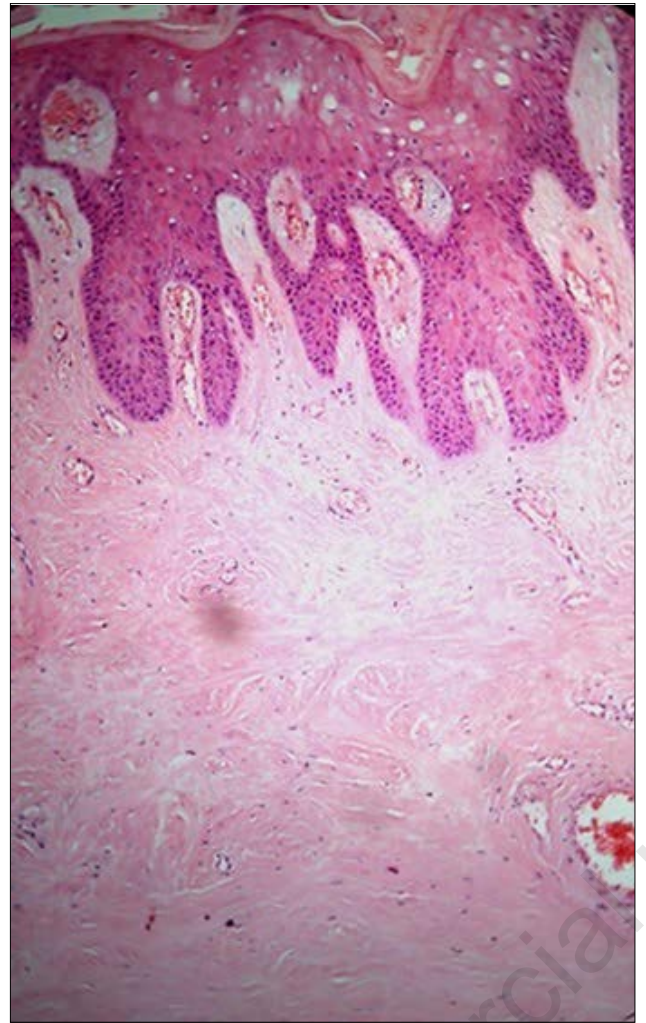

Figure 2

A fibrobronchoscopy with bronchioloalveolar lavage (BAL) was performed which, macroscopically, suggested a diffuse alveolar hemorrhage. Cytological examination of the BAL revealed the presence of macrophages, $85 \%$ of which were positive for hemosiderin with the Perls' Prussian blue stain.
Based on these preliminary results, a pulse therapy with methylprednisolone $(1 \mathrm{~g}$ for three consecutive days) was indicated, followed by oral prednisone at a dose of $1 \mathrm{mg} /$ $\mathrm{kg} /$ day. Given the possibility of an infectious etiology, antibiotics were initiated empirically.

During his second day of hospitalization, an insidious abdominal pain appeared. Physical examination showed no signs of peritoneal irritation. An X-ray of the abdomen and, later, a CT revealed intestinal dilation with no signs of obstruction or inflammation.

During the third day, the patient exhibited more tachypnea, prolonged expiration and coarse crackles on lung auscultation. Laboratory showed worsening of his metabolic acidosis $\left(\mathrm{pH} \mathrm{7.04} ; \mathrm{HCO}_{3}^{-}\right.$ $6.5 \mathrm{mEq} / \mathrm{L}$ ). Orotracheal intubation was performed and he was transferred to the Intensive Care Unit (ICU), where mechanical ventilation was initiated. While in the ICU, he received renal replacement therapy by hemodialysis and a pulse therapy with intravenous cyclophosphamide. Due to his increasing arterial pressure, the dose of enalapril was gradually augmented. An hemorrhagic fluid was obtained by pericardiocentesis. On cytological analysis, it showed erythrocytes and necrotic cells.

On his ninth day since arrival, he exhibited an increase in abdominal dilation. Surgical intervention was decided upon. The lapa-

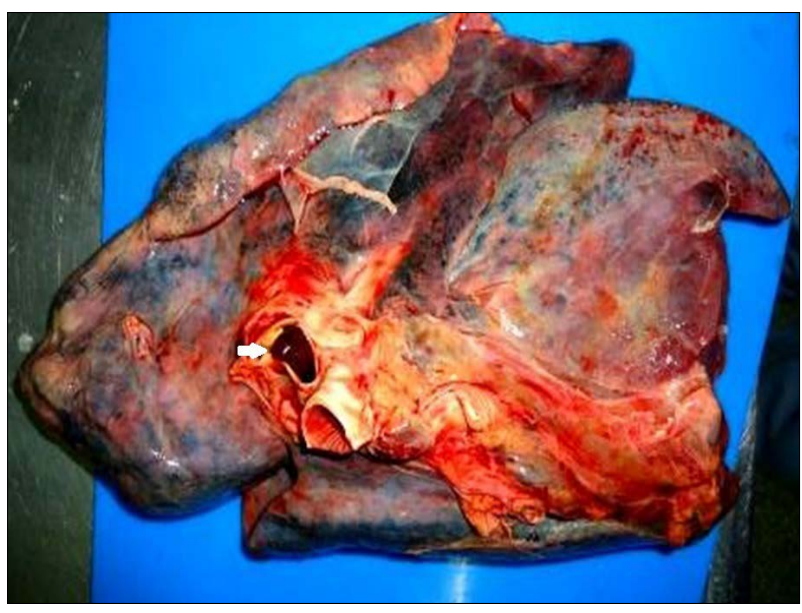

Figure 3 - Right pulmonary artery thrombosis (arrow).

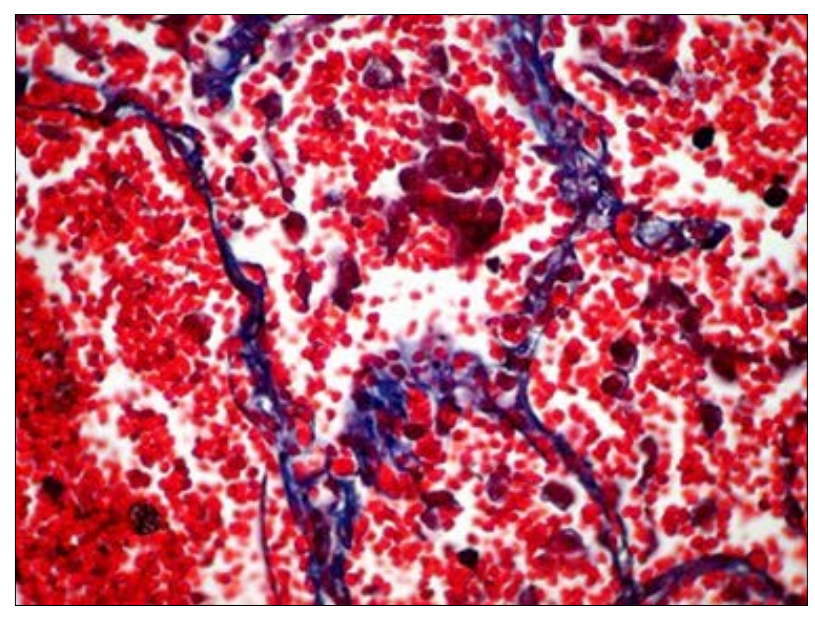

Figure 4 


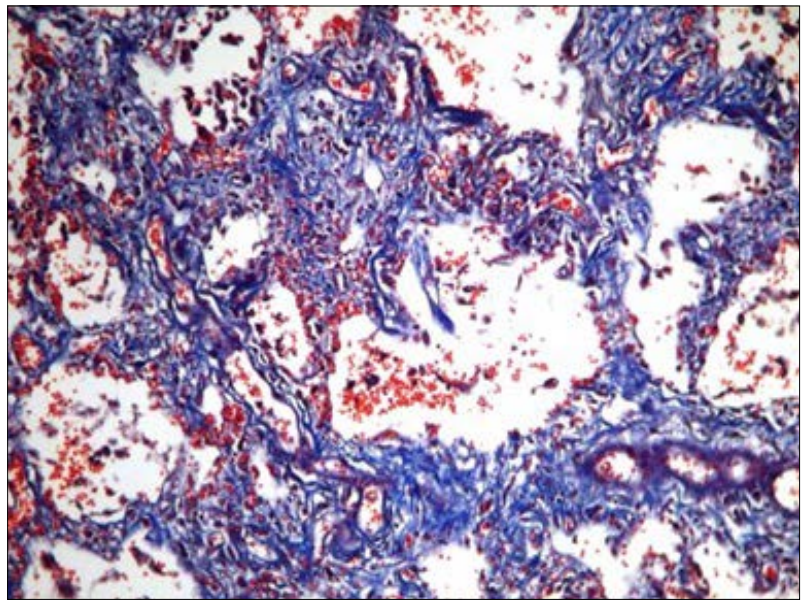

Figure 5

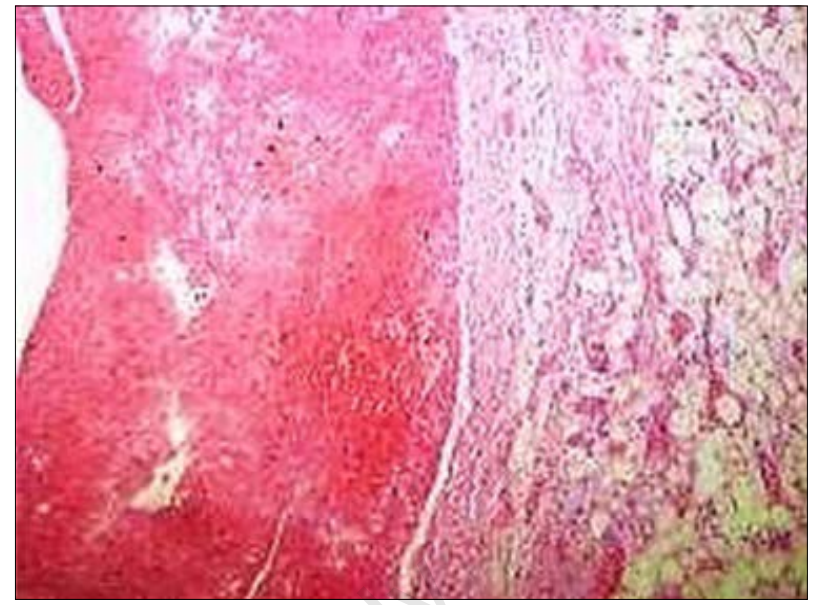

Figure 6 rotomy revealed areas of necrosis on the terminal ileum which was resected. Ultimately, the patient showed signs of hemodynamic instability and died.

After the patient's death, results for antiphospholipid antibodies (aPL), which had been determined on admission, were received: Lupus anticoagulant (LA) was positive and anticardiolipin antibodies and antibodies to $\beta 2$-glicoprotein-I were negative.

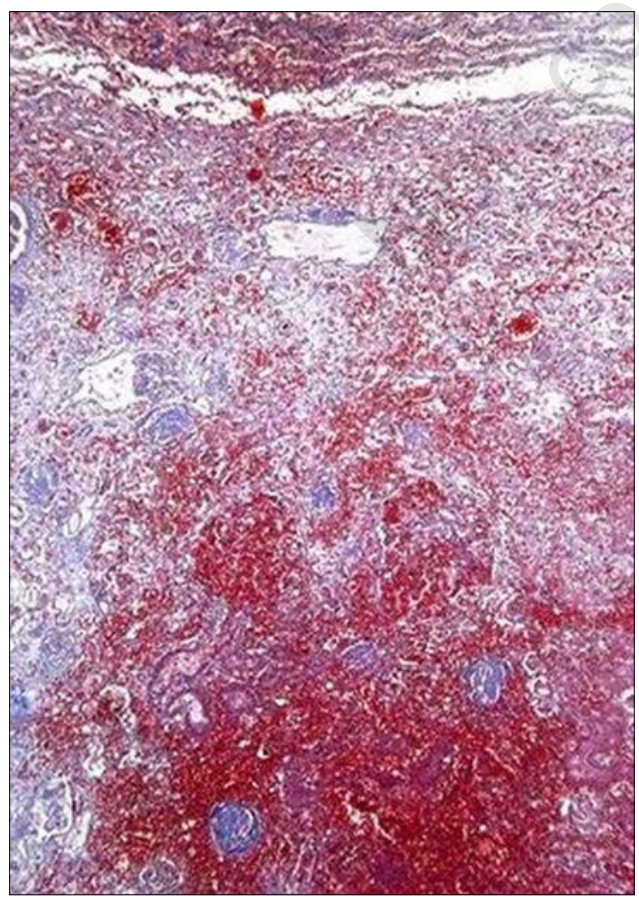

Figure 7
An autopsy was performed with the following findings: diffuse dermic fibrosis (Figure 2), right pulmonary artery thrombosis (Figure 3), diffuse alveolar hemorrhage with no signs of pulmonary vasculitis (Figure 4), pulmonary septal fibrosis (Figure 5), acute hemorrhagic pericarditis (Figure 6), multiple areas of renal cortical necrosis (Figure 7), renal arteriolar and glomerular capillary thrombosis (Figure 8), extensive acute tubular necrosis, splenic infarction with thrombosis of the splenic artery (Figure 9), necrosis of the right fifth toe with thrombosis of the arterioles of the papillary dermis (Figure 10), mucosal necrosis of the distal esophagus and necrosis of the right adrenal gland.

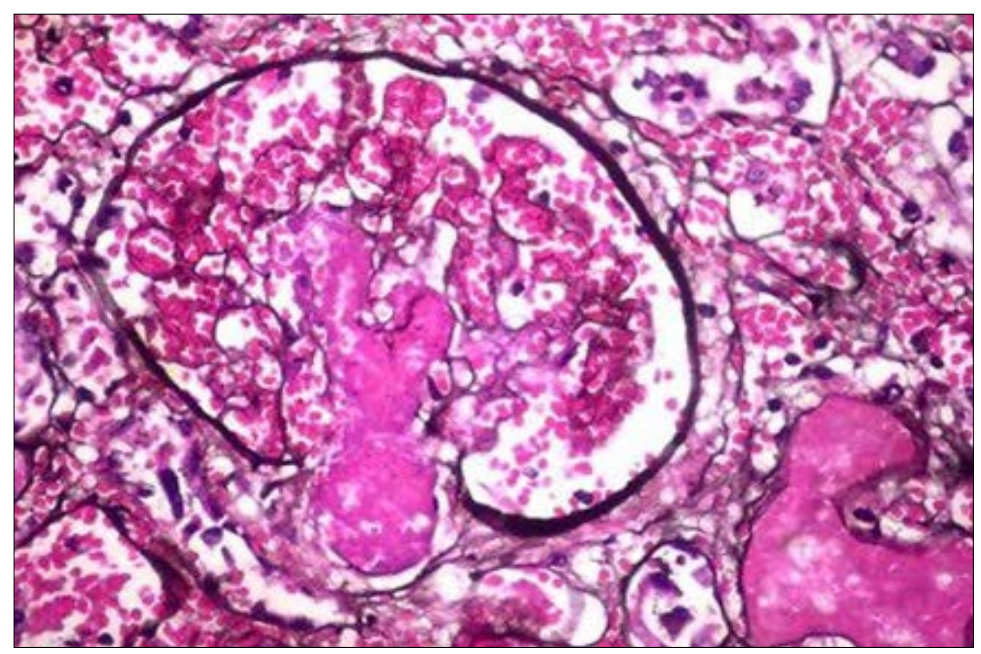

Figure 8 - Glomerular arteriolar thrombosis (methenamine silver stain $\times 400$ ). 
Pathological analysis of the intestinal segment resected before the patient's death showed necrosis and thrombosis of submucosal vessels (Figure 11).
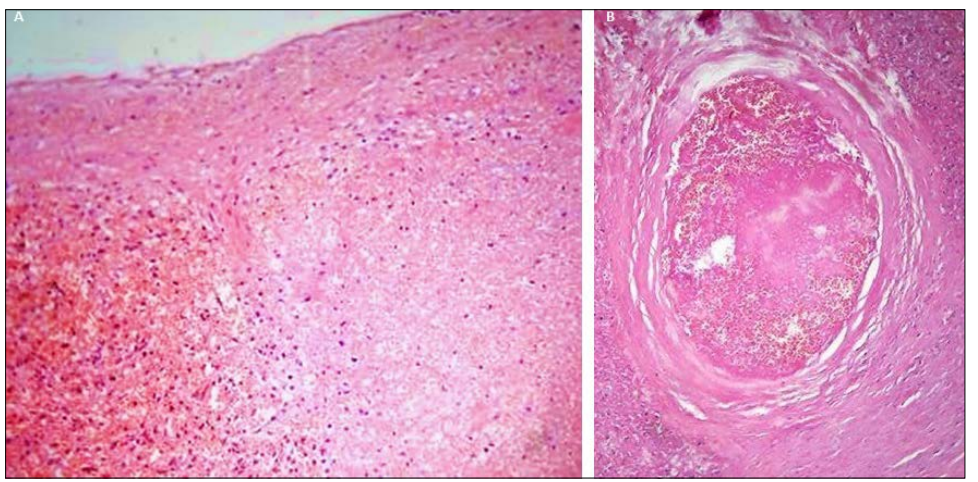

Figure 9
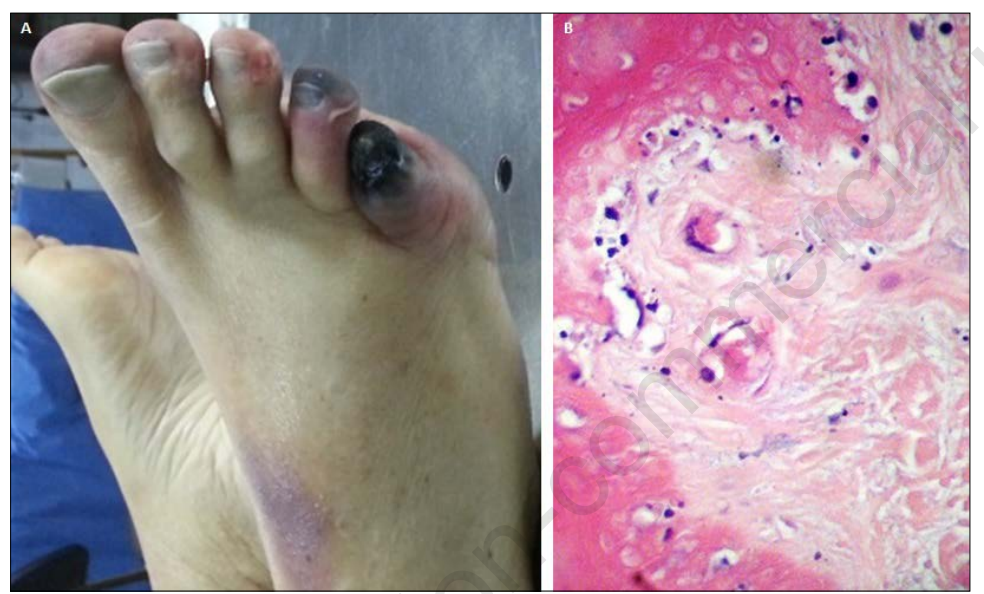

Figure 10

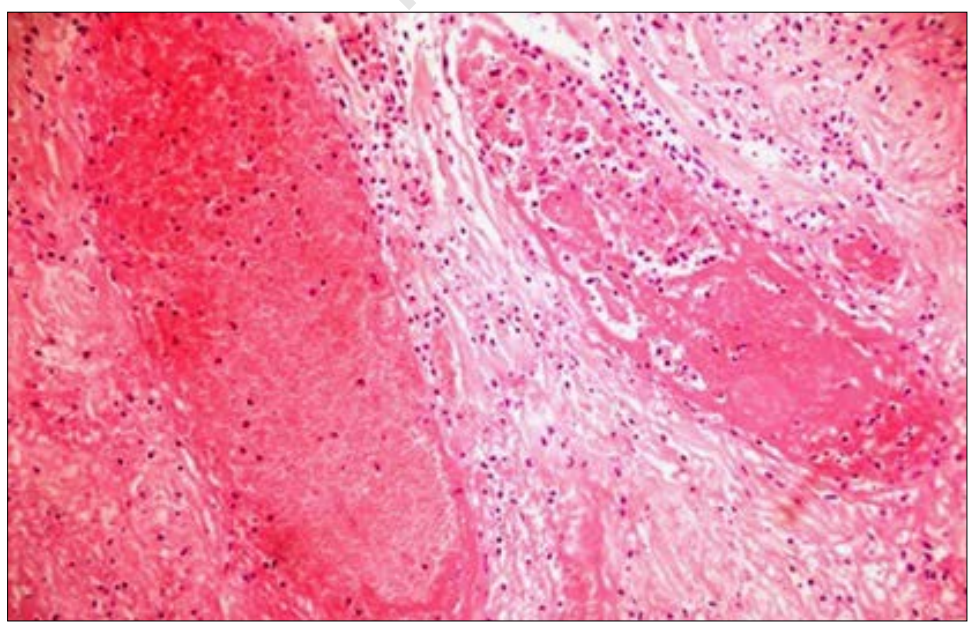

Figure 11

\section{DISCUSSION AND CONCLUSIONS}

Pulmonary renal syndrome (PRS) has been defined as the concurrence of diffuse alveolar hemorrhage and glomerulonephritis $(3,4)$. The ANCA related primary vasculitides and anti-GBM antibody disease (Goodpasture's) are among its most frequent etiologies but it has also been described in other autoimmune diseases such as systemic lupus erythematosus (SLE) and, less frequently, systemic sclerosis (SSc). Specifically, in the latter, PRS is an extremely rare complication that appears later in the disease and indicates a poor prognosis.

The PRS that develops in association with SSc obeys one of two physiopathological mechanisms: an ANCA positive or negative small vessel vasculitis or an anti-GBM antibody disease-like syndrome induced by D-penicillamine (5). In the first case, the vessel injury derives from the activation of neutrophils provoked by ANCA (ANCA positive) or by immunocomplex deposit on the capillary vessels of the lung and glomeruli (ANCA negative). The second mechanism - as in the proper anti GBM antibody disease (Goodpasture's) - depends on the existence of an antibody directed towards an antigen expressed mainly in the glomerular basement membrane and the pulmonary alveoli, inducing glomerulonephritis and pulmonary capillaritis. This mechanism has been described in systemic sclerosis patients treated with D-penicillamine.

A third mechanism for the PRS has been proposed in patients with SSc consisting in thrombotic microangiopathy (6). Nevertheless, this would not be strictly a PRS because glomerulonephritis is not present, as the acute kidney injury is provoked by a different physiopathological process.

Ours was a patient with a history of SSc who was admitted with a diffuse alveolar hemorrhage and an acute kidney injury. Even though PRS was a possibility, clinical data failed to show any evidence of glomerulonephritis as urinalysis showed 
isomorphic erythrocytes and no red cell casts, suggesting that the underlying mechanism of the acute kidney injury was different from glomerulonephritis. In this line of reasoning, systemic vasculitis, anti GBM antibody disease and systemic sclerosis or other autoimmune diseasesrelated PRS would have been expected to show glomerular sediment. The absence of glomerulonephritis was confirmed on autopsy.

Scleroderma renal crisis occurs in 5 to $10 \%$ of patients with diffuse cutaneous SSc (7) and constitutes another possible etiology for the patient's acute disease. However, even though it presents with acute onset of renal failure, urinalysis in scleroderma renal crisis is usually unremarkable and this entity would not be sufficient to explain this patient's other systemic manifestations, such as the pulmonary and intestinal involvement or the necrosis seen in these and other organs as spleen, pericardium or skin.

Catastrophic antiphospholipid syndrome is the most severe form of APS and is characterized by multiple organ failure and widespread thrombotic disease. Its diagnosis is extremely difficult to confirm as it requires the fulfillment of several criteria and its acute and often fatal form of presentation usually prevents the physician from obtaining the appropriate data. Criteria for diagnosis of CAPS includes:

1) clinical evidence of multiple organ involvement developing over a short period of time;

2) histopathological evidence of small vessel occlusions;

3) laboratory confirmation of aPL (lupus anticoagulant (LA) test; anticardiolipin antibody (aCL) enzyme linked immunosorbent assay (ELISA), and/or anti$\beta 2$-glycoprotein-I antibody (a $\beta 2 \mathrm{GPI})$ ELISA).

The $14^{\text {th }}$ International Congress on aPL Task Force maintains previous recommendations for classifying a probable or definite CAPS (8). Considering these recommendations, this patient would have initially been catalogued as a probable
CAPS. The only criteria lacked for establishing a definite CAPS is a confirmation of the aPL at least 6 weeks after the first test, which was impossible to obtain as the patient died.

Even though the International Society on Thrombosis and Haemostasis guidelines on laboratory criteria for antiphospholipid syndrome recommends that an isolated LA should be considered with caution (9), CAPS may arise in many scenarios in which the physician will count with just an isolated determination of aPL and won't be able to postpone decision making.

The aPL Task Force accounts for those scenarios by cataloguing those cases as probable CAPS and not rejecting the diagnosis based on the lack of the confirmatory test. An aPL determination from earlier stages may have significant value in these kinds of situations. As it could explain the diffuse alveolar hemorrhage, the acute kidney injury without glomerulonephritis, the intestinal, splenic, pericardial and digital necrosis, we considered CAPS as the most probable diagnosis. This conclusion was confirmed by the autopsy and was registered as the cause of death.

Few cases of CAPS in association with systemic sclerosis have been published (10-12) and mortality is extremely high. Other reports attributed similar findings to a scleroderma pulmonary renal syndrome which would consist of a combination of a scleroderma renal crisis and diffuse alveolar hemorrhage $(1,2)$ but do not strictly constitute a pulmonary renal syndrome since glomerulonephritis was not part of the pathophysiological mechanism of the acute renal failure. Moreover, these reports failed to report results of aPL; thus, the diagnosis of a CAPS could have been missed.

We believe that considering the association of acute kidney injury and diffuse alveolar hemorrhage in a patient with systemic sclerosis as a scleroderma pulmonary renal syndrome, without consideration of CAPS can lead to an underdiagnosis of the latter, especially when there is no evidence of glomerulonephritis. 


\section{REFERENCES}

1. Bar J, Ehrenfeld M, Rozenman J, et al. Pulmonary-renal syndrome in systemic sclerosis. Semin Arthritis Rheum. 2001; 30: 403-10.

2. Badwal S, Kotwal J, Varma PP. Unusual case of pulmonary renal syndrome with autopsy findings. Indian J Pathol Microbiol. 2013; 56: 294-6.

3. Papiris SA, Manali ED, Kalomenidis I, et al. Bench-to-bedside review: pulmonary-renal syndromes - an update for the intensivist. Crit Care. 2007; 11: 213.

4. Gallagher H, Kwan JT, Jayne DR. Pulmonary renal syndrome: a 4-year, single-center experience. Am J Kidney Dis. 2002; 39: 42-7.

5. Risso JA, Mazzocchi O, De All J, Gnocchi CA. [Pulmonary renal syndrome]. Medicina (B. Aires) 2009; 69: 663-73.

6. Naniwa T, Banno S, Sugiura Y, et al. Pulmonary-renal syndrome in systemic sclerosis: a report of three cases and review of the literature. Mod Rheumatol. 2007; 17: 37-44.

7. Denton CP, Lapadula G, Mouthon L, MüllerLadner U. Renal complications and sclero- derma renal crisis. Rheumatology (Oxford). 2009; 48: iii32-5.

8. Cervera R, Rodríguez-Pintó I, Colafrancesco $\mathrm{S}$, et al. $14^{\text {th }}$ International Congress on Antiphospholipid Antibodies Task Force Report on Catastrophic Antiphospholipid Syndrome. Autoimmun Rev. 2014; 13: 699-707.

9. Devreese KMJ, Ortel TL, Pengo V, de Laat B. Subcommittee on Lupus Anticoagulant/ Antiphospholipid Antibodies. Laboratory criteria for antiphospholipid syndrome: communication from the SSC of the ISTH. J Thromb Haemost. 2018; 16: 809-13.

10. Kane D, McSweeney F, Swan N, Bresnihan B. Catastrophic antiphospholipid antibody syndrome in primary systemic sclerosis. J Rheumatol. 1998; 25: 810-2.

11. Ciołkiewicz M, Domysławska I, Kita K, et al. [Secondary lethal catastrophic antiphospholipid syndrome in 24-years old female patient with overlap syndrome (systemic sclerosis and systemic lupus erythematosus)]. Pol Merkur Lekarski. 2006; 20: 337-40.

12. Sinico RA, Di Toma L, Sabadini E, et al. Catastrophic antiphospholipid syndrome: report of 4 cases. J Nephrol. 2007; 20: 739-44. 